\title{
Protein oxidative changes in whole and skim milk after ultraviolet or fluorescent light exposure
}

\author{
D. Scheidegger, ${ }^{*}$ R. P. Pecora,†¥ P. M. Radici, ${ }^{*}$ and S. C. Kivatinitz ${ }^{* 1}$ \\ *Departamento de Química Biológica-CIQUIBIC, Facultad de Ciencias Químicas, Universidad Nacional de Córdoba, Córdoba, Argentina \\ †Cátedra de Bromatología y Toxicología, Departamento de Química Industrial y Aplicada, Facultad de Ciencias Exactas, Físicas y Naturales, \\ Universidad Nacional de Córdoba, Córdoba, Argentina \\ łInstituto A. P. de Ciencias Básicas y Aplicadas, Universidad Nacional de Villa María, Villa María, Córdoba, Argentina
}

\section{ABSTRACT}

We investigated how protein changes occur, at the primary or higher structural levels, when proteins are exposed to UV or fluorescent (FL) light while in the complex matrix, milk. Whole milk (WM) or skim milk (SM) samples were exposed to FL or UV light from 0 to $24 \mathrm{~h}$ at $4^{\circ} \mathrm{C}$. Protein oxidation was evaluated by the formation of protein carbonyls (PC), dityrosine bond (DiTyr), and changes in molecular weight (protein fragmentation and polymerization). Oxidative changes in AA residues were measured by PC. Dityrosine and N'formylkynurenine (NFK), a carbonylation derivative of Trp, were measured by fluorometry. Protein carbonyls increased as a function of irradiation time for both WM and SM. The initial rate for PC formation by exposure to FL light $(0.25$ or $0.27 \mathrm{nmol} / \mathrm{h}$ for $\mathrm{WM}$ and $\mathrm{SM}$, respectively) was slower than that following exposure to UV light (1.95 or $1.20 \mathrm{nmol} / \mathrm{h}$, respectively). The time course of NFK formation resembled that of PC. After $24 \mathrm{~h}$ of UV exposure, SM had significantly higher levels of NFK than did WM. In contrast, WM samples irradiated with UV had higher levels of DiTyr than did SM samples, indicating different molecular pathways. The formation of intra- or intermolecular DiTyr bonds could be indicative of changes in the tertiary structure or oligomerization of proteins. The existence of NFK suggests the occurrence of protein fragmentation. Thus, proteolysis and oligomerization were analyzed by sodium dodecyl sulfate-PAGE. After $24 \mathrm{~h}$ of exposing WM to UV or FL light, all the proteins were affected by both types of light, as evidenced by loss of material in most of the bands. Aggregates were produced only by UV irradiation. Hydrolysis by pepsin and enzymeinduced coagulation by rennet were performed to evaluate altered biological properties of the oxidized proteins. No effect on pepsin digestion or rennet coagulation was found in irradiated SM or WM. The oxidative status

Received July 8, 2010.

Accepted July 25, 2010.

${ }^{1}$ Corresponding author: skivat@dqb.fcq.unc.edu.ar of proteins in milk and dairy products is of interest to the dairy industry and consumers. These findings provide knowledge that could be useful in determining the optimal lighting conditions in the dairy industry in general and in cheese making in particular.

Key words: milk protein, protein oxidation, light exposure

\section{INTRODUCTION}

The oxidative status of milk and dairy products is of interest to the dairy industry and consumers. Oxidation of milk can result in off-flavors, making the oxidized milk unacceptable to consumers and causing a decrease in the nutritional quality (Dunckley et al., 1962; Dimick and Kilara, 1983; Marsili, 1999). Both UV and visible light wavelengths contribute to the development of aroma compounds in milk (Rosenthal, 1992; Bosset et al., 1993). Singlet oxygen, created during the cascade of photochemical reactions, reacts with lipids, proteins, and vitamin compounds to initiate formation of oxidation products with unpleasant off-flavors (Hansen and Skibsted, 2000; Davies, 2003). Free radicals, generated by autooxidation reactions, are unstable and contribute further to the accumulation of secondary metabolites with effects on flavor and aroma.

Exposure of milk to light can take place at several stages from the time of milking until it is consumed. Previous works (Dimick and Kilara, 1983) report that light-induced protein oxidation in dairy products proceeds quickly and is detected after only a short exposure to light. Sandmeier (1996) noted that the reaction had no induction time.

Photooxidation affects the primary structure of proteins, producing changes in individual amino acids as carbonyl formation, and loss of aromatic amino acids has been described for several complex food matrices (Viljanen et al., 2005). Formation of protein carbonyls (PC) has been shown to be one of the salient changes in oxidized proteins and the concentration of $\mathrm{PC}$ is highly indicative of protein oxidation (Fenaille et al., 2006). Kynurenine and N'-formylkynurenine (NFK), a 
carbonylation product of Trp, have been used as reporters of hen lysozyme denaturation by thermal treatment (Fukunaga et al., 1982).

The aromatic amino acids Trp, Tyr, and Phe have absorption maxima at wavelengths around 280 to 290 nm (Wetlaufer, 1962). Direct photochemical changes to protein are restricted to high-energy UV light because they have very limited absorption at wavelengths longer than $310 \mathrm{~nm}$ (Mortensen et al., 2004). Some earlier investigations on the effects of light on milk dealt with sensory aspects and the ability of milk to clot when renneted (Wishner, 1964; White and Bulthaus, 1982). Photooxidation of His residues causes $\kappa-\mathrm{CN}$ and whole $\mathrm{CN}$ to lose their ability to clot when renneted (Hill and Wake, 1969). In those works, the causes of the deleterious aromas were assigned mainly to the oxidation of lipid and riboflavin. Catalytic photoaggregation and photodegradation of purified $\alpha-\mathrm{LA}, \beta-\mathrm{LG}$, and acid whey proteins isolated from homogenized milk have been described (Gilmore and Dimick, 1979). More recently, the effect of irradiation on individual isolated protein oxidation has been studied. Oxidative changes involving Trp residues and formation of dityrosines (DiTyr) have been noted (Dalsgaard et al., 2008), along with decreased accessibility of chymosin to oxidized caseins (Dalsgaard and Larsen, 2009).

The formation of protein polymers between whey proteins and casein components has been described for thermal-treated milk (Singh et al., 1996). Denaturation of $\beta$-LG seems to be the key phenomenon that initiates polymer formation (Anema, 2000) and has been proposed as a marker of heat processed milk (Chen et al., 2005). Heat induces a conformational change that results in the exposure of a reactive thiol group, which forms disulfide bonds with other cysteine-containing proteins such as BSA, or with proteins having disulfide bridges, such as $\alpha-\mathrm{LA}, \kappa-\mathrm{CN}$, and $\alpha_{\mathrm{S}_{2}} \mathrm{CN}$ (Roefs and de Kruif, 1994; Vasbinder et al., 2001). Heat treatment of milk results in a complex mixture of native whey proteins and denatured whey proteins present as whey protein aggregates, $\mathrm{CN}$-whey protein aggregates, and whey protein-coated CN micelles (Vasbinder et al., 2003).

Therefore, this study aimed to investigate the changes introduced into milk proteins at the primary or higher structural levels by UV or fluorescent (FL) light oxidation while in their natural complex matrixwhole milk (WM) or skim milk (SM). Oxidation was determined by the formation of PC and DiTyr, and by alteration in the molecular weights of proteins to detect polymerization and proteolysis. In addition, we assayed hydrolysis by pepsin and clotting by rennet because it has been demonstrated that photooxidation influences hydrolysis by proteases. The relationship between our observations and milk quality preservation is discussed. These findings provide knowledge that could aid in determining optimal lighting conditions in the dairy industry in general and in cheese making in particular.

\section{MATERIALS AND METHODS}

\section{Materials}

2,4-Dinitrophenylhydrazin (DNPH) and pepsin (P6887, activity: 3,260 units/mg protein) were purchased from Sigma (Sigma-Aldrich, Steinheim, Germany). N,N'-Methylene-bis-acrylamide and acrylamide were from Sigma (Sigma Chemical Co., St. Louis, MO). Guanidine hydrochloride (ultrapure) was from Genbiotech (Capital Federal, Argentina), TCA, glacial acetic acid, ethyl acetate, ethyl alcohol, and hydrochloride acid were from Cicarelli (San Lorenzo, Argentina). All of these products are of analytical grade.

\section{Milk Samples}

Commercially processed spray-dried WM was used (SanCor, Sunchales, Argentina).Whole milk powder was reconstituted to $13 \%$ total solids as indicated on the label. To obtain SM, reconstituted WM was defatted by centrifugation at $7,500 \times g$ for $15 \mathrm{~min}$ at $4^{\circ} \mathrm{C}$ (centrifuge $5804 \mathrm{R}$, Eppendorf AG, Hamburg, Germany) and then filtered through glass wool.

\section{Experimental Design}

Samples of $5 \mathrm{~mL}$ (WM or $\mathrm{SM}$ ) were poured into 6-cm-diameter Petri dishes and exposed to FL or UV light inside a chamber $(30 \mathrm{~cm}$ high, $50 \mathrm{~cm}$ long, and 20 $\mathrm{cm}$ wide) from 0 to $24 \mathrm{~h}$ at $4^{\circ} \mathrm{C}$. Simultaneously, control samples were exposed to the same conditions but were wrapped in aluminum foil to avoid exposure to light.

The FL lamp was an Alic Daylight (15 W/F15T8, $230 \mathrm{~V}$; Alic, Hefei, China), with an intensity of 2,090 to 2,100 lx, and the UV lamp was an $\mathrm{Hg}$ UV-C TUV Philips tube (15 W/G15T8; Philips, Eindhoven, Holland), with an intensity of $2.34 \times 10^{19}$ quanta/s as assessed by ferrioxalate actinometry.

\section{Protein Quantification}

Protein concentration was determined by UV spectroscopy at $280 \mathrm{~nm}$ or by following the Bradford method (Bradford, 1976) using BSA as standard.

\section{Measurement of Dityrosine and NFK}

Protein solutions $(1 \mathrm{mg} / \mathrm{mL})$ were analyzed for the presence of dityrosine (DiTyr) by fluorometry, and 
measurements were performed using an SLM 4800C fluorometer (SLM/Aminco, American Instrument Company, Urbana, IL) equipped with a xenon-arc lamp using an 8-nm bandwidth. Formation of DiTyr was monitored by the increase in fluorescence using excitation and emission wavelengths of 325 and 410 $\mathrm{nm}$, respectively, as reported previously (Heinecke et al., 1993; Artola et al., 1997). Dityrosine has a characteristic emission spectrum of authentic standard with a maximum at $410 \mathrm{~nm}$ (Capeillère-Blandin et al., 1991). N-Formylkynurenine was measured using an excitation wavelength of $325 \mathrm{~nm}$ and an emission wavelength of $435 \mathrm{~nm}$ (Fukunaga et al., 1982).

\section{Measurement of Protein Carbonyls}

The methodology was adapted from Levine et al. (1990) as previously reported (Fenaille et al., 2006). An aliquot of aqueous milk solution (2 $\mathrm{mg}$ of protein) was incubated with $10 \mathrm{mM}$ DNPH in $2 \mathrm{M} \mathrm{HCl}(1 \mathrm{~mL}$ volume), for $30 \mathrm{~min}$ at room temperature. Milk proteins were precipitated with $10 \%$ (wt/vol) TCA (final concentration) and recovered by centrifugation for 5 $\min$ at 7,500 $\times g$ (Micromax RF centrifuge, International Equipment Company, Needham, MA). Protein pellets were washed 3 times with $1 \mathrm{~mL}$ of ethanol/ethyl acetate 50:50 ( $\mathrm{vol} / \mathrm{vol})$ to remove free $\mathrm{DNPH}$ reagent and redissolved in $1 \mathrm{~mL}$ of $6 \mathrm{M}$ guanidine hydrochloride, $\mathrm{pH}$ 2.3. Protein carbonyls were determined by UV spectrophotometry at $370 \mathrm{~nm}$ using an extinction coefficient of $2.2 \times 10^{4} M^{-1} \mathrm{~cm}^{-1}$, with a Mini Spec UV-vis spectrophotometer (Shimadzu, Kyoto, Japan). Results were expressed as nanomoles of carbonyl per milligram of protein.

\section{SDS-PAGE}

Sodium dodecyl sulfate-PAGE was performed according to Jovanovic et al. (2007), using a $3 \%$ polyacrylamide stacking gel and a $15 \%$ separating gel. Before electrophoresis, milk samples were diluted 25 times in distilled deionized water, mixed with Laemmli sample buffer containing $2.5 \% \beta$-mercaptoethanol, and boiled for $5 \mathrm{~min}$ (Laemmli, 1970). The vertical electrophoresis unit Mini-Protean III system (BioRad Corp., Richmond, CA) was used in conjunction with the Bio-Rad Power PAC 3000 power supply. The gel was stained with $0.25 \%$ Coomassie Blue R-250 for 90 min, and destained in the methanol:acetic acid solution (20\% methanol, $10 \%$ acetic acid). Destained gels were scanned (Epson Stylus TX115 scanner, Capital Federal, Argentina) and quantified by densitometry analysis free software Image
J (National Institutes of Health, Bethesda, MD; http:/ / rsbweb.nih.gov/ij/).

\section{Pepsin Digestion}

In vitro pepsin digestion was performed at an enzyme to substrate ratio of 1:100 (wt/wt) using a porcine pepsin solution of $7.0 \mathrm{mg} / \mathrm{mL}$ (P6887, activity of 3,260 units/mg of protein; Sigma-Aldrich) and samples of 30 $\mathrm{mg} / \mathrm{mL}$ protein. Samples $(60 \mu \mathrm{L})$ were added to a microtube with $225 \mu \mathrm{L}$ of $0.1 \mathrm{M} \mathrm{HCl}$ and $15 \mu \mathrm{L}$ of pepsin solution. The samples were incubated for $0,15,30$, and $60 \mathrm{~min}$ at $37^{\circ} \mathrm{C}$. Digestion was stopped with the addition of $10 \mathrm{~m} M$ Tris $-0.01 \%$ EDTA, $\mathrm{pH}$ 9. Proteins $(20 \mu \mathrm{g})$ were resolved by SDS-PAGE in a $15 \%$ polyacrylamide gel, Coomassie stained, and quantified by densitometry analysis using the Image $\mathrm{J}$ software.

\section{Enzyme-Induced Coagulation}

A laboratory assay described by Melilli et al. (2002) was used with minor modifications. Calcium $(400 \mu \mathrm{L}$ of $20 \% \mathrm{wt} / \mathrm{vol}$ solution) was added to preweighed tubes containing $5 \mathrm{~mL}$ of WM. Samples were placed into a water bath at $40^{\circ} \mathrm{C}$ and incubated for $10 \mathrm{~min}$. Then, $0.6 \mathrm{~mL}$ of chymosin (microbial origin: Mucor miehei, Clerici-Sacco Group, Cadorago, Italy) diluted 1:5,000 in distilled water was added to each tube. Samples were mixed on a vortex for $15 \mathrm{~s}$ and incubated in a water bath at $40^{\circ} \mathrm{C}$ for $30 \mathrm{~min}$. After this time, a firm coagulum was formed. Tubes were centrifuged (centrifuge $5804 \mathrm{R}$, Eppendorf AG) at 1,200 $\times g$ for $30 \mathrm{~min}$. The supernatant was carefully removed, and the tubes were placed upside down on absorbent paper for $1 \mathrm{~h}$ and then weighed (fresh curd yield). Finally, pellets were subjected to lyophilization and weighed again (dry curd yield). Fresh curd yield and dry curd yield were expressed as percentage of weight relative to control sample weight (Hallén et al., 2010).

\section{Statistical Analysis}

Kinetic curves and rate constants of the averaged data were generated by using SimFit software (version 6.0.18, University of Manchester, Manchester, UK; http://www.simfit.man.ac.uk). Data points were the mean \pm SEM of 3 separate experiments, each with triplicate determinations. Statistical comparison of nonlinear regression models was performed by an $F$-test using the extra sums of squares principle. Nonlinear least squares regression was done using programs SimFit or GraphPad PRISMk 4.02 (GraphPad Software, 


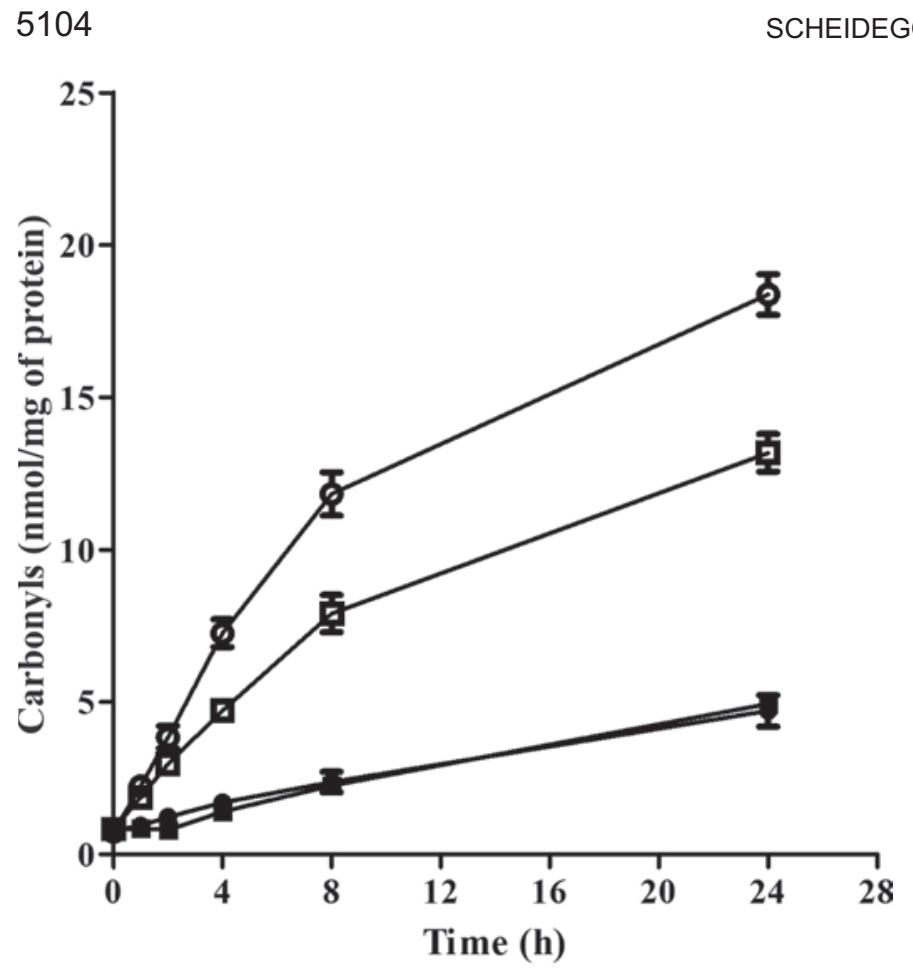

Figure 1. Kinetics of protein carbonyl generation by UV or fluorescent photooxidation. Protein carbonyls were determined in milk exposed to UV or fluorescent (FL) light by the colorimetric method of Levine et al. (1990), as a function of time of exposure to radiation. $=$ whole milk (WM) exposed to FL light; $\bullet=$ skim milk (SM) exposed to FL light; $\square=\mathrm{WM}$ exposed to UV light; and $\bigcirc=\mathrm{SM}$ exposed to UV light. Results were expressed as nanomoles of carbonyls per milligram of protein and represent the average \pm SEM of triplicate experiments

San Diego, CA). Experiments were performed at least in replicates of triplicate samples.

\section{RESULTS AND DISCUSSION}

\section{Changes in the Primary Structure of Proteins}

Changes in amino acid residues were measured by formation of carbonyl groups, DiTyr bonds, and a carbonylation derivative of Trp, NFK. It was observed that PC increased as a function of irradiation time for WM and SM (Figure 1). When WM or SM samples were irradiated with UV light, PC increased following a first-order kinetic reaction; the monomolecular model gave the best fit (Table 1). Interestingly, the initial rate of PC formation was higher for SM than for WM. The kinetic parameters of $\mathrm{PC}$ formation following exposure to FL light were indistinguishable for WM and SM, likely indicating that lipids were not involved in the mechanism. Under FL irradiation, the curves fit better with the logistic model, indicating the existence of a latency delay in the onset of the reaction. The initial rate for PC formation by FL light was several times slower than that following UV light irradiation.

Few reports exist on the formation of PC by photooxidation or thermal treatments used in dairy product processing (Scaloni et al., 2002). It has been reported that isolated caseins developed an increase in carbonyl content because of the oxidation of Try, His, and Met after photooxidation by FL exposure (Dalsgaard et al., 2007). Moreover, PC formation in milk during processing had been studied and no correlation could be observed for lipid or protein oxidation (Fenaille et al., 2006). It is interesting to note that carbonyl formation by UV irradiation was different for whole and defatted milk, indicating that lipids conferred higher stability to oxidative photooxidation (Figure 1, Table 1). This observation could help to explain why, although lipid and protein oxidation can occur simultaneously and show synergistic effects, it is difficult to state whether lipid or protein species are more sensitive toward oxidation (Fenaille et al., 2006). Our results may provide an explanation for the lack of correlation observed in gas chromatography of volatile compounds originated from lipid and nonfat dry milk off-flavors determined by sensory analysis and suggests that protein carbonyl moieties could contribute to off-flavors without being detected by the chemical technique employed (KaragülYüceer et al., 2004).

Fluorescence spectra analysis allowed us to discern the oxidation of Tyr and Try to DiTyr and NFK, respectively. We observed that both AA oxidation products increased rapidly (until $8 \mathrm{~h}$ ) in milks irradiated with UV or FL light; the extent of formation of DiTyr

Table 1. Kinetic parameters of protein carbonyl generation ${ }^{1}$

\begin{tabular}{|c|c|c|c|c|c|c|}
\hline Light & Sample & $\begin{array}{c}\text { Initial rate } \\
(\mathrm{nmol} / \mathrm{h})\end{array}$ & $\begin{array}{l}\text { Asymptote } \\
\text { (nmol) }\end{array}$ & Constant & Best fit model & $\mathrm{r}^{2}$ \\
\hline UV & Whole milk & 1.20 & $15.3 \pm 2.5$ & & Monomolecular & 0.998 \\
\hline UV & Skim milk & 1.95 & $21.2 \pm 0.5$ & & Monomolecular & 0.997 \\
\hline FL & Whole milk & 0.25 & $5.2 \pm 0.1$ & $0.200 \pm 0.010$ & Logistic & 0.996 \\
\hline FL & Skim milk & 0.27 & $4.80 \pm 0.06$ & $0.233 \pm 0.009$ & Logistic & 0.995 \\
\hline
\end{tabular}

${ }^{1}$ Analysis of UV or FL (fluorescence)-irradiated whole milk or skim milk was performed using Simfit from data depicted in Figure 1 . The \pm refers to standard errors based on the curve fitting using the monomolecular or logistic models. These equations were chosen because they provided the best fit (based on the pattern of residuals and the lowest residual sum of squares). 

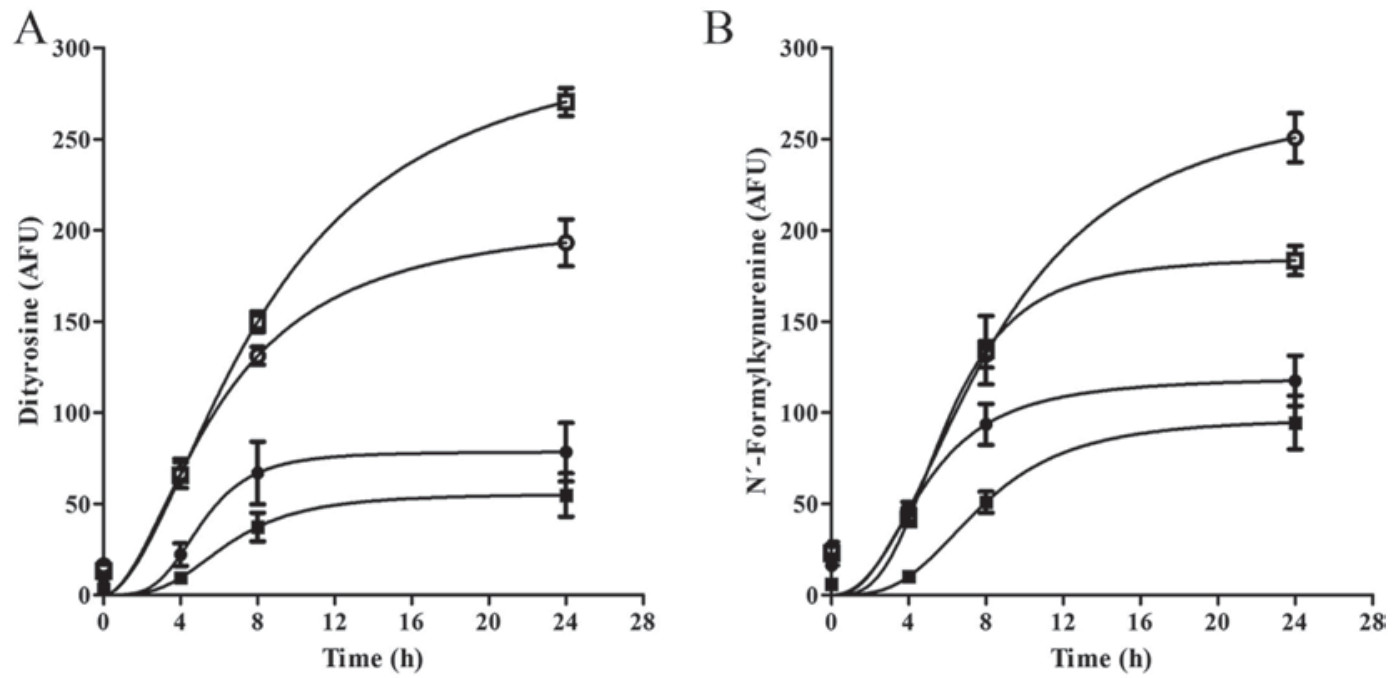

Figure 2. Kinetics of (A) dityrosine and (B) N'-formylkynurenine (NFK) formation by UV or fluorescent (FL) light exposure. Dityrosine and NFK were determined by fluorescence spectroscopy in an aliquot of $1 \mathrm{mg} / \mathrm{mL}$ of milk protein from milk exposed to UV or FL light, as a function of time. Excitation and emission were performed at $315 \mathrm{~nm}$ and $410 \mathrm{~nm}$, respectively, for dityrosine, and $325 \mathrm{~nm}$ and $435 \mathrm{~nm}$, respectively, for NFK. $\mathbf{\square}=$ whole milk (WM) exposed to FL light; $\bullet=$ skim milk (SM) exposed to FL light; $\square=\mathrm{WM}$ exposed to UV light; and $\bigcirc=$ SM exposed to UV light. Results were expressed as arbitrary fluorescence units (AFU) of the sample minus AFU of control and represent the mean \pm SEM of triplicates. One representative experiment of 3 different experiments is shown.

or NFK was higher under UV irradiation than with FL light exposure (Figure 2, panel A and B). After 24 $\mathrm{h}$ of UV irradiation, WM had higher levels of DiTyr and lower levels of NFK than did SM. At this time, no significant differences could be observed between SM and WM exposed to FL irradiation. Under similar illumination conditions $\left(2,000 \mathrm{~lx}\right.$ at $4^{\circ} \mathrm{C}$ for $\left.24 \mathrm{~h}\right)$, Havemose et al. (2006) were unable to find differences in DiTyr formation for 2 types of milk with different fatty acid compositions. The time course of NFK formation resembled that of PC (Figure 1 and Figure 2, panel B), corroborating the findings in $\mathrm{CN}$ exposed to FL light (Dalsgaard and Larsen, 2009). After $24 \mathrm{~h}$ of UV exposure, SM had significantly higher levels of NFK compared with WM $(251 \pm 23$ and $183 \pm 14$, respectively; $P<0.04)$. Contrastingly, significantly higher levels of DiTyr were found in WM than in SM $(270 \pm 13$ and 193 \pm 22 , respectively; $P<0.02$ ) indicating, most probably, different molecular pathways of formation.

The formation of DiTyr in photooxidized milk suggests that changes in the tertiary structure or oligomerization of proteins can occur and the existence of Trp derivatives could be indicative of protein cleavage.

\section{Proteolysis and Aggregation}

To determine proteolysis and oligomerization, we analyzed the electrophoretic mobility of milk proteins. Milk proteins were resolved by electrophoresis under reducing and denaturing conditions. After $24 \mathrm{~h}$ of expo- sure of WM to UV or FL light, all the resolved proteins were affected by both types of illumination; loss of substance in most of the bands could be observed after 8 $\mathrm{h}$ of exposure (Figure 3). The decrease in total protein recovery after $24 \mathrm{~h}$ of irradiation could be attributed to proteolysis and it was greater for UV than for FL light exposure (Figure 3). The level of aggregates was not affected by FL irradiation but increased steeply following UV light exposure to reach more than twice the initial value after $24 \mathrm{~h}$. The occurrence of aggregates in UV-exposed milk could explain the greater loss of protein under these irradiation conditions. The occurrence of aggregates by UV exposure (Figure 3 ) is also in accordance with the occurrence of higher levels of DiTyr bond formation (Figure 2, panel A). These results identify a new covalent bond involved in milk protein oligomerization because, until now, oligomer formation was thought to be the result of the disulfide interaction among $\kappa-\mathrm{CN}, \beta-\mathrm{LG}$, and $\alpha$-LA in both heattreated milk (Carbonaro et al., 1998; Nabhan et al., 2004; Jovanovic et al., 2007) and in fluorescent or sunirradiated milk for periods longer than $90 \mathrm{~h}$ (Gilmore and Dimick, 1979).

The time course of decrease in CN closely followed that of total protein. This result was expected because $\mathrm{CN}$ is the most abundant protein in milk (about 70 $80 \%$ ). The most affected protein was $\alpha$-LA, irrespective of the type of irradiation; only $30 \%$ remained after 24 $\mathrm{h}$ of FL irradiation and it was undetectable after the same period of UV exposure. 
FL

BSA
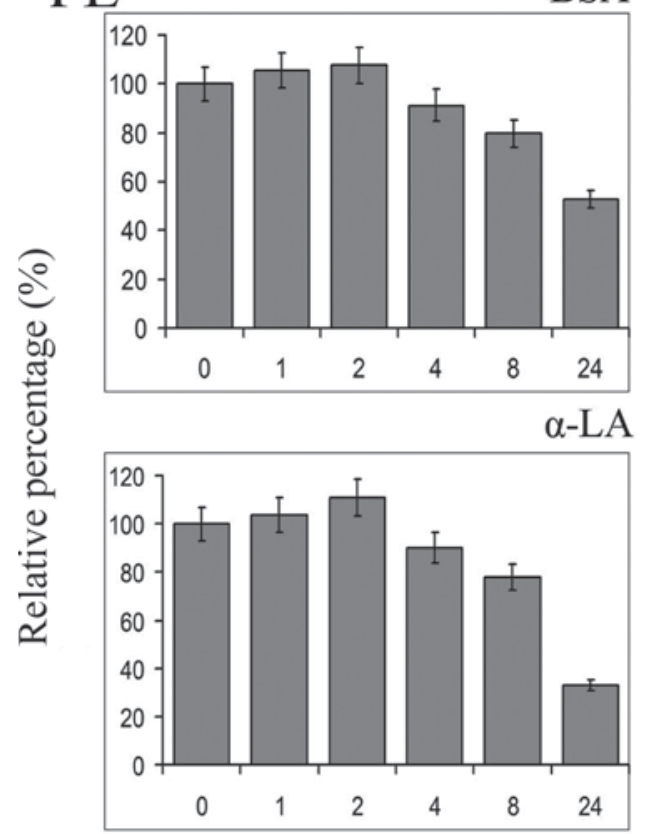

UV

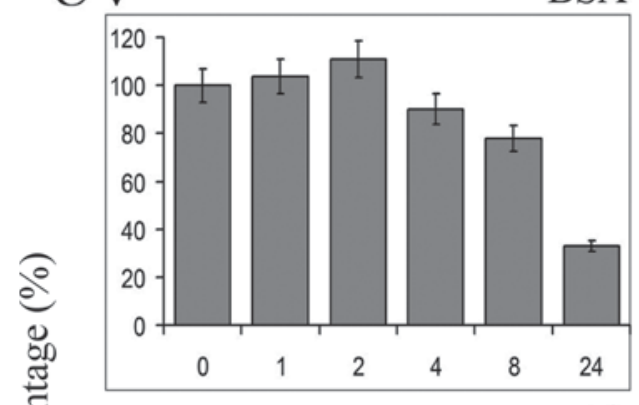

$\alpha$-LA

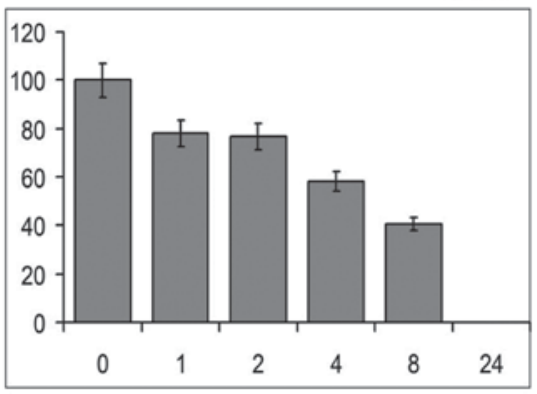

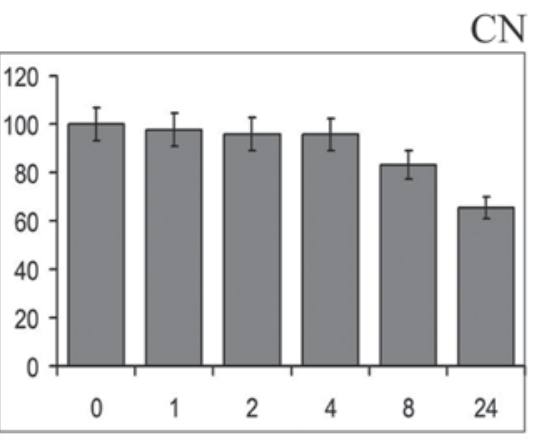

Total Proteins

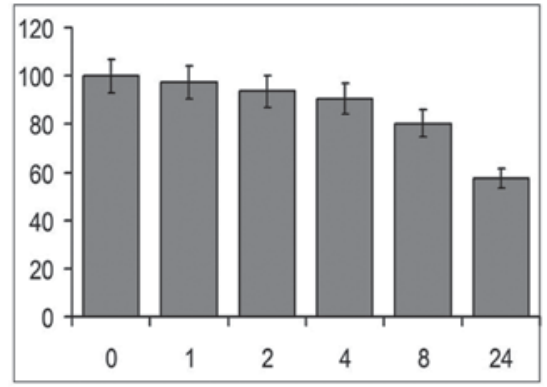

Time (h)

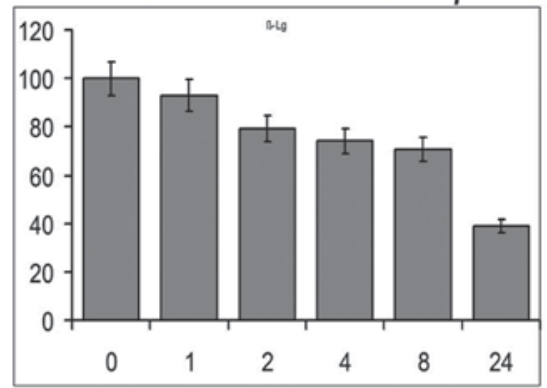

Aggregates

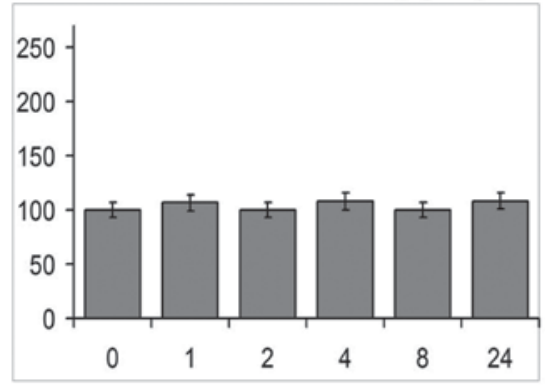

$\beta$-LG

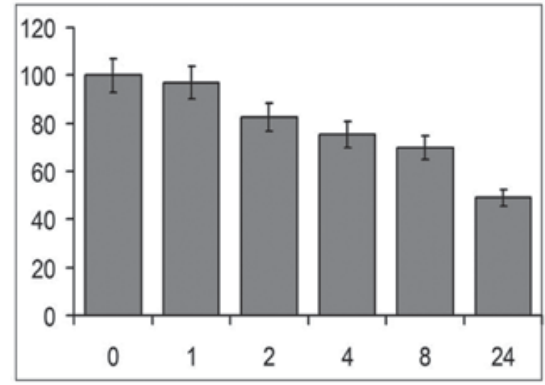

Total Proteins

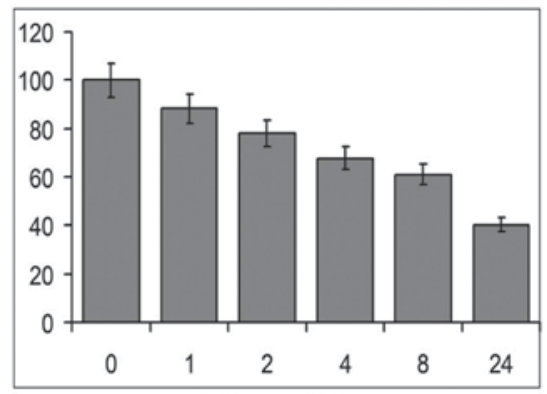

Time (h)

Figure 3. Kinetics of individual milk protein levels by (FL) fluorescent or UV photooxidation. Milk samples were exposed for the indicated time to light. Proteins were resolved and quantified by densitometry analysis of the SDS-PAGE. Results of statistical analyses were performed on the densitometric analysis of the digitalized gel images. Each band represents an average \pm SEM of 3 measurements of independent SDSPAGE experiments. Results are expressed as the average percentage ratio of pixels of a band in relation to the corresponding ones of the band from the unexposed sample. Aggregates in whole milk (WM) exposed to different types of light were measured as a relative percentage of time zero, which was $100 \%$ (without light exposure), as a function of time. Data were taken from the densitometry analysis of the proteins retained in the stacking gel used in the SDS-PAGE with 2-mercaptoethanol. 

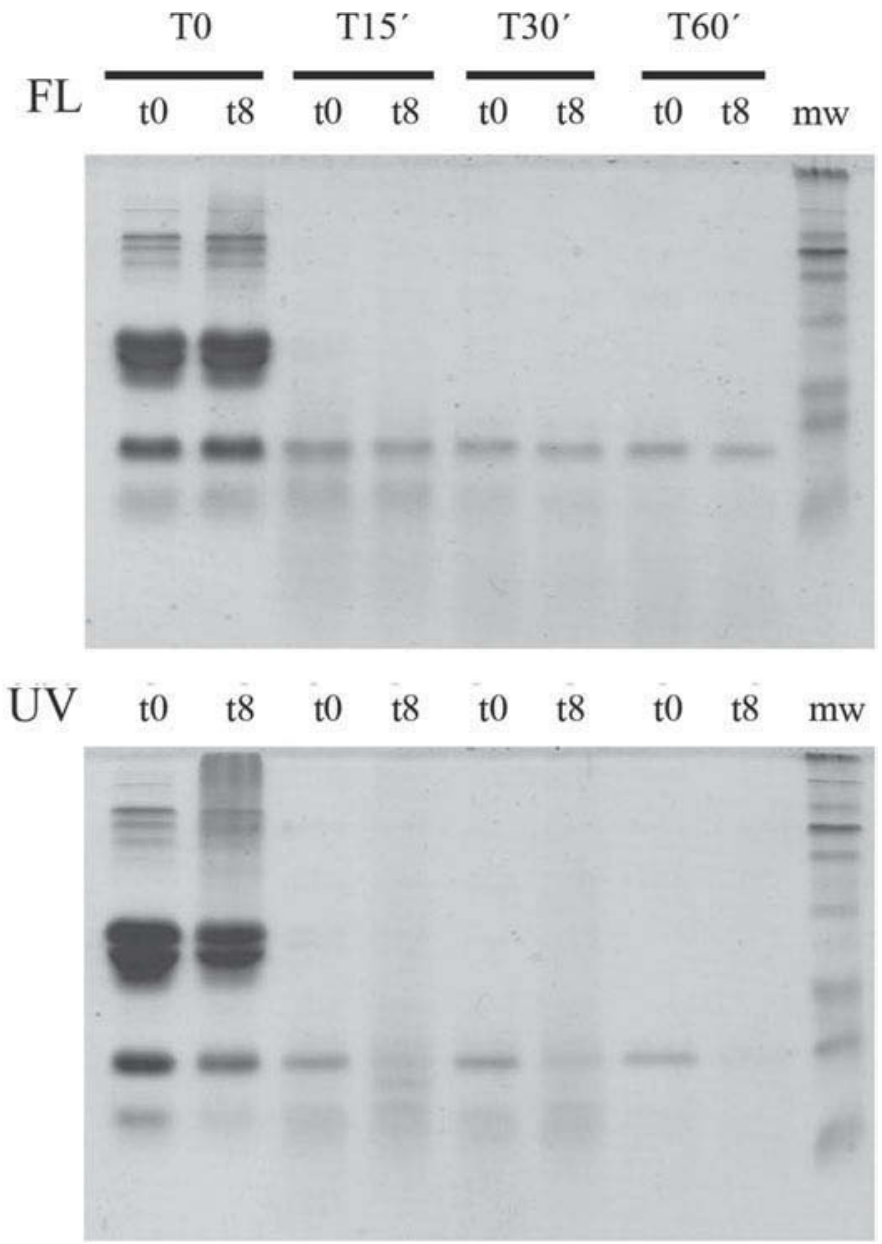

Figure 4. Effect of fluorescent (FL) or UV irradiation on pepsin digestion. Proteins of irradiated milk samples were extensively digested by pepsin. Proteins of digested milk samples were resolved by SDSPAGE under reducing conditions. Samples were exposed to light for 0 $\mathrm{h}$ or $8 \mathrm{~h}$ ( $\mathrm{t} 0$ or t8, respectively), and digested with pepsin for $0,15,30$, or $60 \mathrm{~min}$ (T0, T15', T30', and $\mathrm{T} 60^{\prime}$, respectively).

Table 2 shows that the relationship between casein and whey protein increased after FL or UV irradiation. These data could be of immunological importance because the balance between caseins and whey proteins is thought to determine allergenicity (Lara-Villoslada et al., 2005). Our results are not in agreement with those found when using isolated milk proteins subjected to FL irradiation because caseins are more labile toward oxidation than are the more compact globular whey proteins (Dalsgaard et al., 2007), but are in agreement with the concept that the behavior of isolated components is difficult to relate to that of the whole original mix (Mazzocchi, 2008).

It has been previously suggested that the accessibility of whey proteins to proteolytic enzymes depends on the extent of aggregation because the in vitro digestibility of total whey extracts proteins is progressively impaired as a function of the intensity of the heat treatment (Carbonaro et al., 1997, 1998). Aggregation of proteins suggests that proteolysis by digestive enzymes (pepsin and chymosin) could be hampered, thus reducing some functional properties of milk. Therefore, the final experiment was designed to evaluate pepsin digestion and clotting of WM after exposure to UV and FL.

\section{Enzymatic Proteolysis of Milk Exposed to Different Types of Light}

Proteins of milk subjected to pepsin digestion after being exposed to UV or fluorescence irradiation for $8 \mathrm{~h}$ were cleaved as easily as those in unexposed milk. After 15 min of enzymatic activity, the remaining undigested protein was less than $2 \%$ of the initial content (Figure 4).

Light exposure did not affect the partition of milk proteins in the curd: the retention of protein in the dried pellet obtained after chymosin incubation was similar to that of the unexposed sample (Figure 5). The small decrease in dry mass observed after $24 \mathrm{~h}$ of UV exposure could be related to proteolysis at this time $(100 \pm 2 \%$ and $95 \pm 2 \%$ for control and UV, respectively; $P<0.03)$. The increase in water retention in the curd of WM exposed to UV (Figure 5) could be due to hydrophobicity changes of casein molecules as observed in CN exposed to FL light (Dalsgaard et al., 2008) or aggregation of whey proteins subjected to thermal treatment (Carbonaro et al., 1998).

Table 2. Ratio of casein to whole whey protein after fluorescent (FL) or UV exposure ${ }^{1}$

\begin{tabular}{lcccccc}
\hline & \multicolumn{3}{c}{ Exposure time $(\mathrm{h})$} & & \multicolumn{2}{c}{ Significance $(P \leq)$} \\
\cline { 2 - 3 } Light & 0 & 4 & 24 & & $0-4 \mathrm{~h}$ & $0-24 \mathrm{~h}$ \\
\hline FL & $2.1 \pm 0.1$ & $2.5 \pm 0.2$ & $3.3 \pm 0.3$ & & 0.02 & 0.02 \\
UV & $2.2 \pm 0.1$ & $3.4 \pm 0.3$ & $5.5 \pm 0.4$ & & 0.01 & 0.002 \\
\hline
\end{tabular}

${ }^{1}$ Milk samples were exposed in triplicate to FL or UV light for 0,4 , or $24 \mathrm{~h}$. Milk proteins were resolved and quantified by densitometry analysis of SDS-PAGE under reducing conditions. Results are expressed as the average \pm SEM of the relationship: $\mathrm{CN} /$ (whey proteins). Individual bands were determined by the densitometric analysis of digitalized gel images using Image J software. Differences between FL and UV were significant after $4 \mathrm{~h}(P \leq 0.02)$ and $24 \mathrm{~h}(P \leq 0.01)$. 


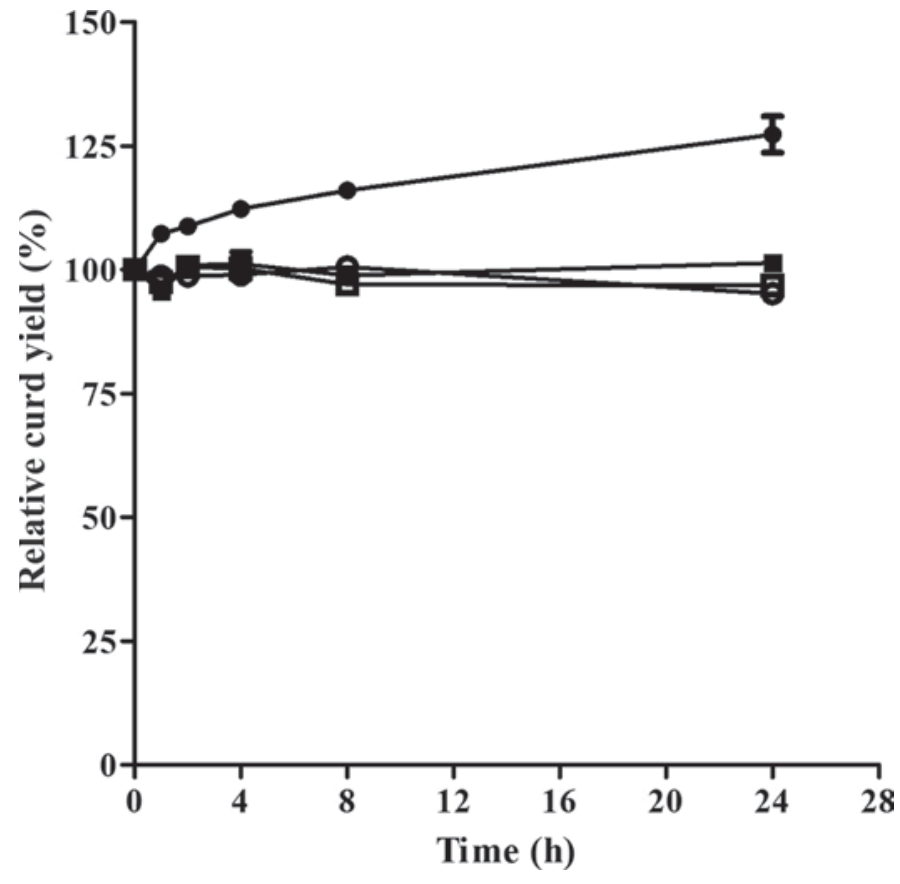

Figure 5. Effect of fluorescent (FL) or UV irradiation on milk-clotting capacity. $\bullet$ and $\boldsymbol{\square}=$ fresh curd yield from whole milk (WM) exposed to UV light and to FL light, respectively; $\bigcirc$ and $\square=$ lyophilized yield from WM exposed to UV light and to FL light, respectively. Results were expressed as the percentage mean \pm SEM of triplicates, considering $100 \%$ the yield of the corresponding unexposed sample.

\section{CONCLUSIONS}

We report the protein oxidation of whole or skimmed reconstituted milk under irradiation with UV or FL light. All chemical parameters tested showed oxidative effects by both types of lights. One important finding was that the appearance of carbonyl moieties was detected as early as after $1 \mathrm{~h}$ of UV and $4 \mathrm{~h}$ of FL lighting, suggesting carbonyl analysis as a putative candidate for protein oxidation testing. Another relevant finding was that FL irradiation for a 4-h period produced several changes in addition to carbonyl formation, such as the appearance of dityrosine bonds and the alteration of whey to casein balance. The results of enzymatic proteolysis (pepsin and chymosin) suggest that the aggregation and cleavage of proteins produced by light exposure would not affect enzymatic proteolysis for cheese making. The latter finding is relevant for dairy industry, particularly for cheese manufacturers, because it is possible that milk could be exposed to fluorescent light for periods longer than $4 \mathrm{~h}$ from the time of milking until it reaches consumers. Our results are the first report of a detailed study of protein photooxidation in complete whole or skim milk, and they show that some of the features described for the isolated proteins are similar to what happens to total milk, but other distinctive reactions occurred only in the complex matrix.

\section{ACKNOWLEDGMENTS}

We thank Carlos Argaraña and José Carlos Prospero Romano for critical reading of the manuscript and María Rita Afonso for English correction. Grant support was from SeCyT, Universidad Nacional de Córdoba; Instituto de Investigación del Rectorado, Universidad Nacional de Villa María. DS is recipient of CONICET-MinCyT-Córdoba scholarship as a student of the doctoral career.

\section{REFERENCES}

Anema, S. G. 2000. Effect of milk concentration on the irreversible thermal denaturation and disulfide aggregation of $\beta$-lactoglobulin. J. Agric. Food Chem. 48:4168-4175.

Artola, R. L., C. B. Conde, L. Bagatolli, R. P. Pecora, G. D. Fidelio, and S. C. Kivatinitz. 1997. High density lipoprotein form hypercholesterolemic animals has peroxidized lipids and oligomeric apolipoprotein A-I: Its putative role in atherogenesis. Biochem. Biophys. Res. Commun. 239:570-574.

Bosset, J. O., P. U. Gallmann, and R. Sieber. 1993. Influence de la translucidité de l'emballage sur la conservation du lait et des produits laitersun article de revue. Lait 73:3-49.

Bradford, M. M. 1976. A rapid and sensitive method for the quantitation of microgram quantities of proteins utilizing the principle of protein dye binding. Anal. Biochem. 72:248-254.

Capeillère-Blandin, C., T. Delaveau, and B. Descamps-Latscha. 1991. Structural modifications of human $\beta 2$-microglobulin treated with oxygen-derived radicals. Biochem. J. 277:175-182.

Carbonaro, M., F. Bonomi, S. Iametti, M. Cappelloni, and E. Carnovale. 1998. Aggregation of proteins in whey from raw and heatprocessed milk: Formation of soluble macroaggregates and nutritional consequences. Lebensm. Wiss. Technol. 31:522-529.

Carbonaro, M., M. Capelloni, S. Sabbadini, and E. Carnovale. 1997. Disulfide reactivity and in vitro protein digestibility of different thermal-treated milk samples and whey proteins. J. Agric. Food Chem. 45:95-100.

Chen, W. L., M. T. Hwang, C. Y. Liau, J. C. Ho, K. C. Hong, and S. J. T. Mao. 2005. $\beta$-lactoglobulin is a thermal marker in processed milk as studied by electrophoresis and circular dichroic spectra. J. Dairy Sci. 88:1618-1630.

Dalsgaard, T. K., C. W. Heegaard, and L. B. Larsen. 2008. Plasmin digestion of photo-oxidized milk proteins. J. Dairy Sci. 91:21752183.

Dalsgaard, T. K., and L. B. Larsen. 2009. Effect of photo-oxidation of major milk proteins on protein structure and hydrolysis by chymosin. Int. Dairy J. 19:362-371.

Dalsgaard, T. K., D. Otzen, J. H. Nielsen, and L. B. Larsen. 2007. Changes in Structure of Milk Proteins upon Photo-oxidation. J. Agric. Food Chem. 55:10968-10976.

Davies, M. J. 2003. Singlet oxygen-mediated damage to proteins and its consequences. Biochem. Biophys. Res. Commun. 305:761770 .

Dimick, P. S., and A. Kilara. 1983. Photo-oxidative changes in milk proteins and amino acids. Pages 289-299 in Role of Milk Proteins in Human Nutrition. W. Kaufmann, ed. The Mann Publ., Verlag, Gelsenkirchen-Buer, Germany.

Dunckley, W. L., D. J. Frankel, and R. M. Pangborn. 1962. Effects of fluorescent light on flavor, ascorbic acid, and riboflavin in milk. Food Technol. 16:112-118.

Fenaille, F., V. Parisod, P. Visani, S. Populaire, J.-C. Tabet, and P. A. Guy. 2006. Modifications of milk constituents during processing: A preliminary benchmarking study. Int. Dairy J. 16:728-739.

Fukunaga, Y., Y. Katsuragi, T. Izumi, and F. Sakiyama. 1982. Fluorescence characteristics of kynurenine and N'-formylkynurenine, their use as reporters of the environment of tryptophan 62 in hen egg-white lysozyme. J. Biochem. 92:129-141. 
Gilmore, T. M., and P. S. Dimick. 1979. Photochemical changes in major whey proteins of cow's milk. J. Dairy Sci. 62:189-194.

Hallén, E., A. Lundén, T. Allmere, and A. Andrén. 2010. Casein retention in curd and loss of casein into whey at chymosin-induced coagulation of milk. J. Dairy Res. 77:71-76.

Hansen, E., and L. H. Skibsted. 2000. Light-induced oxidative changes in a model dairy spread. Wavelength dependence of quantum yields. J. Agric. Food Chem. 48:3090-3094.

Havemose, M. S., M. R. Weisbjerg, W. L. P. Bredie, H. D. Poulsen, and J. H. Nielsen. 2006. Oxidative stability of milk influenced by fatty acids, antioxidants, and copper derived from feed. J. Dairy Sci. 89:1970-1980.

Heinecke, J. W., W. Li, G. A. Francis, and J. A. Goldstein. 1993. Tyrosyl radical generated by myeloperoxidase catalyzes the oxidative cross-linking of proteins. J. Clin. Invest. 91:2866-2872.

Hill, R. J., and R. G. Wake. 1969. Amphiphile nature of K-casein as the basis for its micelle stabilizing property. Nature 221:635-639.

Jovanovic, S., M. Barac, O. Macej, T. Vucic, and C. Lacnjevac. 2007. SDS-PAGE analysis of soluble proteins in reconstituted milk exposed to different heat treatments. Sensors. 7:371-383.

Karagül-Yüceer, Y., M. A. Drake, and K. R. Cadwallader. 2004. Evaluation of the character impact odorants in skim milk powder by sensory studies on model mixtures. J. Sens. Stud. 19:1-14

Laemmli, U. K. 1970. Cleavage of structural proteins during the assembly of the head of bacteriophage T4. Nature 227:680-685.

Lara-Villoslada, F., M. Olivares, and J. Xaus. 2005. The balance between caseins and whey proteins in cow's milk determines its allergenicity . J. Dairy Sci. 88:1654-1660.

Levine, R. L., D. Garland, C. N. Oliver, A. Amici, I. Climent, A.-G. Lenz, B.-W. Ahn, S. Shattiel, and E. R. Stadtman. 1990. Determination of carbonyl content in oxidatively modified proteins. Methods Enzymol. 186:464-478

Marsili, R. T. 1999. Comparison of solid phase micro-extraction and dynamic headspace method for the gas chromatographic-mass spectrometric analysis of light-induced lipid oxidation products in milk. J. Chromatogr. Sci. 37:17-23.

Mazzocchi, F. 2008. Complexity in biology. Exceeding the limits of reductionism and determinism using complexity theory. EMBO Rep. 9:10-14.

Melilli, C., J. M. Lynch, S. Carpino, D. M. Barbano, G. Licitra, and A. Cappa. 2002. An empirical method for prediction of cheese yield. J. Dairy Sci. 85:2699-2704.
Mortensen, G., G. Bertelsen, B. K. Mortensen, and H. Stapelfeldt. 2004. Light-induced changes in packaged cheeses-A review. Int. Dairy J. 14:85-102.

Nabhan, M. A., J. M. Girardet, S. Campagna, J. L. Gaillard, and Y. Le Roux. 2004. Isolation and characterization of copolymers of $\beta$-lactoglobulin, $\alpha$-lactalbumin, $\kappa$-casein, and $\alpha_{\mathrm{S}_{1} \text {-casein generated }}$ by pressurization and thermal treatment of raw milk. J. Dairy Sci. 87:3614-3622.

Roefs, S. P. F. M., and K. G. de Kruif. 1994. A model for the denaturation and aggregation of $\beta$-lactoglobulin. Eur. J. Biochem. $226: 883-889$.

Rosenthal, I. 1992. Ultraviolet-visible radiation. Pages 54-104 in Electromagnetic Radiations in Food Science. Ed. Advanced Series in Agricultural Sciences; Vol. 19. Springer Verlag, Berlin, Germany.

Sandmeier, D. 1996. Brought into the light. Changes in foods under the influence of light. Lebensmitteltechnik 28:41-45.

Scaloni, A., V. Perillo, P. Franco, E. Fedele, R. Froio, L. Ferrara, and P. Bergamo. 2002. Characterization of heat-induced lactosylation products in caseins by immunoenzymatic and mass spectrometric methodologies. Biochim. Biophys. Acta 1598:30-39.

Singh, H., M. S. Roberts, P. A. Munro, and C. T. Teo. 1996. Acidinduced dissociation of casein micelles in milk: Effect of heat treatment. J. Dairy Sci. 79:1340-1346.

Vasbinder, A. J., A. C. Alting, and K. G. De Kruif. 2003. Quantification of heat-induced casein-whey protein interactions in milk and its relation to gelation kinetics. Colloids Surf. B Biointerfaces $31: 115-123$

Vasbinder, A. J., P. J. J. M. van Mil, A. Bot, and C. G. de Kruif. 2001. Acid-induced gelation of heat-treated milk studied by diffusing wave spectroscopy. Colloids Surf. B Biointerfaces 21:245-250.

Viljanen, K., P. Kylli, E. M. Hubbermann, K. Schwarz, and M. Heinonen. 2005. Anthocyanin antioxidant activity and partition behavior in whey protein emulsion. J. Agric. Food Chem. 53:2022-2027.

Wetlaufer, D. B. 1962. Ultraviolet spectra of proteins and aminoacids. Adv. Protein Chem. 17:303-390.

White, C. H., and M. Bulthaus. 1982. Light activated flavor in milk. J. Dairy Sci. 65:489-494.

Wishner, L. A. 1964. Light induced oxidations in milk. J. Dairy Sci. $47: 216-222$. 